\title{
Protective effects of fisetin against myocardial ischemia/reperfusion injury
}

\author{
LIHUI LONG $^{1}$, XULIANG HAN ${ }^{1}$, XINGMING MA ${ }^{1}$, KAI LI $^{1}$, LINJIE LIU ${ }^{1}$, \\ JUANNI DONG ${ }^{1}$, BEI QIN ${ }^{2}$, KELIN ZHANG ${ }^{3}$, KUAN YANG $^{2}$ and HONGLIN YAN ${ }^{1}$ \\ ${ }^{1}$ Department of Pharmacy, The First Affiliated Hospital of Xi'an Medical University, Xi'an, Shaanxi 710077; \\ ${ }^{2}$ Department of Pharmacology, College of Pharmacy of Xi'an Medical University, Xi'an, Shaanxi 710061; \\ ${ }^{3}$ Department of Cardiovascular Medicine, The First Affiliated Hospital of Xi'an Medical University, \\ Xi'an, Shaanxi 710077, P.R. China
}

Received February 15, 2018; Accepted October 8, 2019

DOI: $10.3892 /$ etm.2020.8576

\begin{abstract}
The underlying mechanism of the myocardial protective effect of fisetin was studied in a rat ischemia/reperfusion injury model. Sprague-Dawley rats were randomly assigned to seven groups and pretreated with different solutions by gavage administration. A rat model of cardiac ischemia/reperfusion injury was established. Plasma levels of Von Willebrand factor (vWF) were determined by ELISA, flow cytometry was used to determine the level of cardiomyocyte apoptosis and 2,3,5-triphenyltetrazolium staining was used to determine the size of myocardial infarcts. Hematoxylin and eosin-stained sections of myocardial tissues were examined for pathological changes. Expressions of nuclear factor (NF)- $\kappa \mathrm{B}$ and matrix metallopeptidase 9 (MMP-9) were measured by immunohistochemistry. Compared with the model group, rats pretreated with fisetin, quercetin and aspirin showed significant prolongation of clotting time, prothrombin time, thrombin time and activated partial thromboplastin time. Fisetin treatment better maintained the integrity of myocardial fibers and nuclear integrity, reduced the percentage of apoptotic myocardial cells, inhibited expression of NF- $\mathrm{B}$, decreased the loss of MMP-9 and reduced nuclear translocation of NF-kB. Rats pretreated with fisetin also demonstrated a significant decrease in plasma levels of vWF. In addition, the protective effect of fisetin on myocardial cells was found to be dose dependent.
\end{abstract}

\section{Introduction}

Coronary heart disease (CHD) is a major contributor to overall mortality. An estimated 3.8 million men and 3.4 million women

Correspondence to: Professor Honglin Yan, Department of Pharmacy, The First Affiliated Hospital of Xi'an Medical University, 48 West Fenghao Road, Lianhu, Xi'an, Shaanxi 710077, P.R. China E-mail: yanhonglin666@163.com

Key words: fisetin, myocardial ischemia/reperfusion model, cell apoptosis, matrix metallopeptidase 9 , nuclear factor- $\kappa \mathrm{B}$, rat model die from CHD every year (1-3). Myocardial ischemia/reperfusion injury is a severe pathological change associated with $\mathrm{CHD}$, which leads to a reduction in heart ejection fraction and causes cardiac decompensation (4). Inhibition of apoptosis to prevent myocardial ischemia/reperfusion injury has long been a therapeutic target (5).

Flavonoids are a class of natural secondary metabolites produced by plants and fungi; their molecular structure is characterized by two phenyl rings and one heterocyclic ring. Flavonoids display antioxidant and antibacterial effects, both in vitro and in patients with cardiovascular disease and cancer (6-8).

Studies conducted on patients with cardiovascular disorders have demonstrated that flavonoids reduce the risk of atherosclerosis and hypertension via attenuation of oxidative stress and the related signaling pathways in blood vessel cells, and by improving endothelial and capillary function $(9,10)$. The main factors involved in inflammation include nuclear factor (NF)- $\mathrm{B}$ and matrix metallopeptidase-9 (MMP-9). The activity of $\mathrm{NF}-\kappa \mathrm{B}$ is primarily regulated by interaction with inhibitor of $\kappa \mathrm{B}(\mathrm{IkB})$ proteins; the $\mathrm{IkB} / \mathrm{NF}-\kappa \mathrm{B}$ interaction is a key step for controlling $N F-\kappa B$ activity. Activation of $N F-\kappa B$ has been widely reported in the context of several diseases including cancer, chronic inflammatory disorders, neurodegenerative diseases, and heart disease (11). Matrix metalloproteinases are associated with post-myocardial infarction left ventricular remodeling with MMP-9 identified as the only circulating factor that predicts late onset of congestive heart failure $(12,13)$.

Fisetin (3,3',4',7-tetrahydroxyflavone) is present in various drugs, fruits and vegetables, such as apples, grapes, onions, and cucumbers (14-16). Studies have demonstrated that fisetin displays a number of beneficial properties, including anticancer, anticoagulatory, anti-inflammatory and antioxidant effects (17-22). Our previous study determined the anticoagulant and thrombolytic effect of fisetin in vitro, using heparin as a positive control (18). However, the cardioprotective effect of fisetin and the underlying mechanism are yet to be studied in vivo. Therefore, the present study explored the potential protective effects of fisetin on ischemic cardiomyocytes and the underlying mechanism in a rat model of myocardial ischemia/reperfusion. 


\section{Materials and methods}

Preparation of reagents and samples. Enteric coated aspirin tablets were provided by Luoyang Mingkang Pharmaceutical Co., Ltd (Luoyang, China). Clopidogrel bisulfate tablets were purchased from Jinan Lekangxin Pharmaceutical Co., Ltd. (Jinan, China). Dipyridamole injection was purchased from Yabao Pharmaceutical Group Co., Ltd. (Ruicheng, China). Adrenaline hydrochloride injection was provided by Tianjin Jinyao Amino Acid Co., Ltd. (Tianjin, China). Aspirin, adenosine 5'-diphosphate disodium salt and arachidonic acid were purchased from Sigma-Aldrich (Merck KGaA, Darmstadt, Germany). Fisetin and quercetin (purity $>98 \%$ ) were purchased from Shaanxi Chang Yue Plant Technology Co., Ltd. (Xi'an, China). Prothrombin Time kit (PT kit), Activated Partial Thromboplastin Time kit (APTT kit) and Thrombin Time kit (TT kit) were purchased from Shanghai Sunred Biological Technology Co., Ltd. (Shanghai, China). NF-кB and MMP-9 detection kits and $5 \%$ bovine serum albumin were provided by Wuhan Boster Biological Technology, Ltd. (Wuhan, China). Annexin V-fluorescein isothiocyanate (FITC)/propidium iodide (PI) apoptosis detection kit was purchased from Nanjing KGI Biological Technology Development Co., Ltd. (Nanjing, China). Other reagents used in the study were of analytical grade.

Animal experiments. Male Sprague-Dawley (SD) rats (age, 8 weeks; weight, 250-300 g) were purchased from the Animal Center of Xi'an Jiaotong University College of Medicine (Xi'an, China). The animals were housed under 12-h light-/dark cycle at $26 \pm 3^{\circ} \mathrm{C} 30-70 \%$ humidity. Ad libitum access to standard rodent chow and water was provided. All animal experiments were approved and conducted according to the experimental protocol authorized by the Ethical Committee of the First Affiliated Hospital of Xi'an Medical College.

Eighty-four SD rats were randomly divided into seven groups: Sham operation group (negative control); model group; three fisetin-pretreated groups $(5,15$ and $45 \mathrm{mg} / \mathrm{kg})$; quercetin-pretreated; and aspirin-pretreated groups. Rats in the sham control and model groups were administered $0.5 \%$ sodium carboxymethyl cellulose (CMC-Na) solution $(10 \mathrm{ml} / \mathrm{kg})$ by gavage administration. Rats in the other groups were pretreated with solutions containing the varying concentrations of fisetin, aspirin or quercetin in $0.5 \% \mathrm{CMC}-\mathrm{Na}$ by gavage administration once per day for 7 days. The dosage of aspirin and quercetin was determined by preliminary experiments and through reference to published literature $(18,23,24)$. On day 8 , rats were anesthetized with $10 \%$ chloral hydrate (350 mg/kg, $4 \mathrm{ml} / \mathrm{kg}$ ) and fixed in the dorsal position for operation. A two-lead electrocardiogram (ECG) was connected to the depilated skin and rats were mechanically ventilated. Tracheotomy was performed for endotracheal intubation. The ventral thorax was incised transversely at the level of intercostal spaces 4 to 6 to expose the heart. The left anterior descending branch was ligated. Successful surgery was confirmed by observing cyanosis around the remote end of myocardium and ST-segment elevation and tall T-waves in ECG (25-27). After $30 \mathrm{~min}$ of ligation, $2 \mathrm{~h}$ of reperfusion was initiated by removing the ligation line (Fig. 1). After $2 \mathrm{~h}$ of reperfusion rats were euthanized. The rats were first anesthetized with
$10 \%$ chloral hydrate $(350 \mathrm{mg} / \mathrm{kg}, 4 \mathrm{ml} / \mathrm{kg})$ and kept areflexive with muscular flaccidity. An $\sim 8 \mathrm{ml}$ volume of blood was then taken from the abdominal aorta leading to rat death, which was confirmed by respiratory and cardiac arrest.

Preparation of drug solution. To prepare $6 \times 10^{-3} \mathrm{~mol} / 1$ fisetin solution, $127 \mu 1 \%$ sodium carbonate $\left(\mathrm{Na}_{2} \mathrm{CO}_{3}\right)$ solution was added into a mixing tube containing $1.72 \mathrm{mg}$ fisetin powder. Quercetin solution $\left(6 \times 10^{-3} \mathrm{~mol} / \mathrm{l}\right)$ was prepared by dissolving $1.81 \mathrm{mg}$ of quercetin in $127 \mu \mathrm{l} 1 \% \mathrm{Na}_{2} \mathrm{CO}_{3}$ solution. Dipyridamole solution $\left(120 \times 10^{-6} \mathrm{~mol} / \mathrm{l}\right)$ was prepared by dissolving $12.1 \mu \mathrm{l}$ dipyridamole $(2 \mathrm{ml}: 10 \mathrm{mg})$ in saline and adjusting the volume to $1 \mathrm{ml}$. Aspirin solution $(3 \mathrm{mg} / \mathrm{ml})$ was prepared by dissolving $3 \mathrm{mg}$ aspirin in $1 \% \mathrm{Na}_{2} \mathrm{CO}_{3}$ solution and adjusting the total volume to $1 \mathrm{ml}$. Clopidogrel $(360 \mu \mathrm{g} / \mathrm{ml})$ was prepared by dissolving $0.36 \mathrm{mg}$ clopidogrel in saline and adjusting the volume to $1 \mathrm{ml}$. Sodium citrate solution (3.8\%) was prepared by dissolving $1.9 \mathrm{~g}$ sodium citrate in saline and adjusting to $50 \mathrm{ml}$. Adrenaline $(120 \mu \mathrm{mol} / \mathrm{l})$ was prepared by dissolving $13.2 \mu \mathrm{l}$ adrenaline hydrochloride injection $(1 \mathrm{mg} / \mathrm{ml})$ with saline and adjusting the volume to $500 \mathrm{ml}$. Adenosine diphosphate (ADP) solution $(3,000 \mu \mathrm{mol} / \mathrm{l})$ was diluted with saline to the desired concentration before use.

Preparation of platelets. Six healthy adult human blood specimens were provided by the First Affiliated Hospital of Xi'an Medical University (Xi'an, China; 3 men and 3 women; age, $33.7 \pm 8.9$ years). The anti-coagulant used was $3.8 \%$ sodium citrate (sodium citrate: Whole blood, 1:9) and blood was drawn from the median cephalic vein. Blood samples were centrifuged at $179 \mathrm{x} g$ for $10 \mathrm{~min}$ to remove the supernatant and platelet-rich plasma (PRP); the remaining sample was centrifuged at $1016 \mathrm{x} \mathrm{g}$ for $10 \mathrm{~min}$ to collect platelet-poor plasma (PPP). The platelet number in PRP was adjusted with PPP to obtain a final platelet count of 250/nl (28). These procedures were performed at room temperature to prevent platelet activation. All six patients provided written informed consent for the collection and use of their blood samples. In addition, the collection and use of the blood samples was approved by the Research Ethics Committee of the Affiliated Hospital of Xi'an Medical University.

Platelet aggregation. Human platelet aggregation was determined using a four-channel platelet aggregation analyzer (SC-2000; Shanghai Tiancheng Science and Technology Ltd, Shanghai, China). PRP samples $(300 \mu 1 ; 250$ platelets/nl) were pooled in the sample cup and treated with saline, fisetin $\left(1 \times 10^{-4}, 1 \times 10^{-5}, 1 \times 10^{-6}, 1 \times 10^{-7}, 1 \times 10^{-8}\right.$ or $\left.1 \times 10^{-9} \mathrm{~mol} / \mathrm{l}\right)$, quercetin $\left(1 \times 10^{-4}, 1 \times 10^{-5}, 1 \times 10^{-6}, 1 \times 10^{-7}, 1 \times 10^{-8}\right.$ or $\left.1 \times 10^{-9} \mathrm{~mol} / \mathrm{l}\right)$, clopidogrel $\left(3 \times 10^{-5} \mathrm{~mol} / \mathrm{l}\right)$, dipyridamole $\left(2 \times 10^{-6} \mathrm{~mol} / \mathrm{l}\right)$ or aspirin $\left(2.8 \times 10^{-4} \mathrm{~mol} / \mathrm{l}\right)$, respectively. Light transmission was first measured following incubation of the sample at $37^{\circ} \mathrm{C}$ for $20 \mathrm{~min}$, and then measured after platelet activation with ADP $(20 \mu \mathrm{mol} / \mathrm{l})$ and adrenaline $(20 \mu \mathrm{mol} / \mathrm{l})$. Light transmission was set as 0 and $100 \%$ for measurement of pure PPP and PRP, respectively. Inhibition of platelet aggregation was calculated according to the following formula: Percentage inhibition $(\%)=[1-($ platelet aggregation of sample/platelet aggregation of control)] x100\%. Each sample was measured in triplicate. 


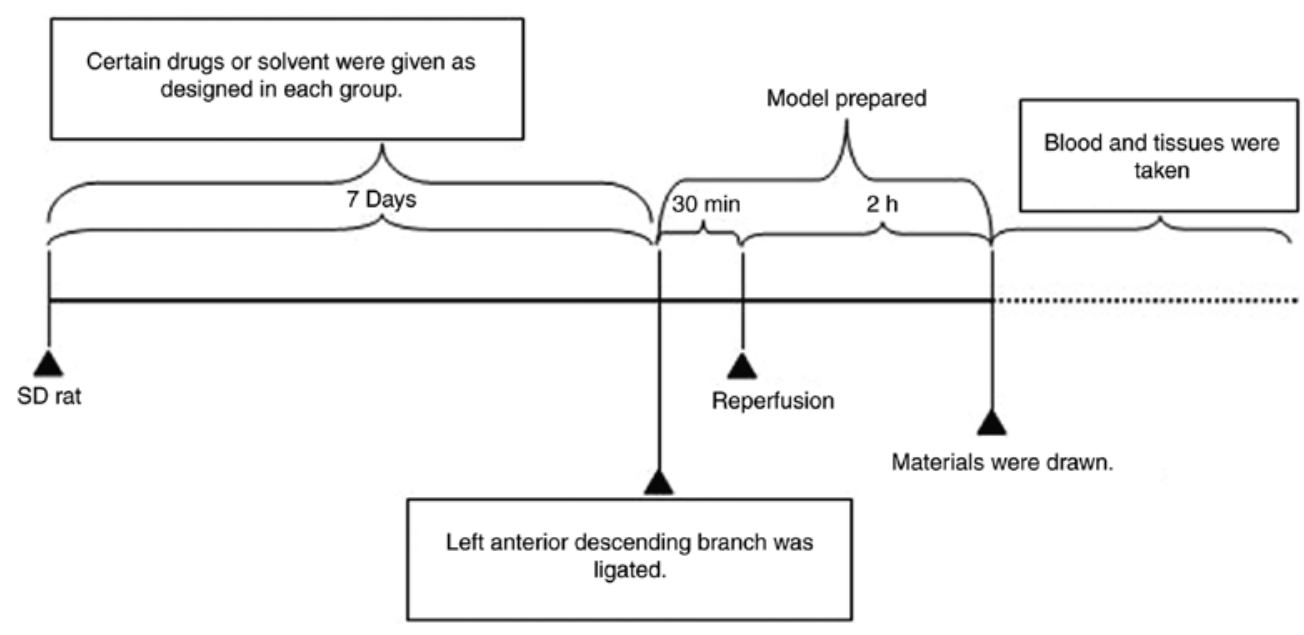

Figure 1. Schematic describing the timeline of the experimental set-up. Rats in each group were pretreated with samples or solvent by gavage administration for 7 days, once a day. On day 8, rats were anesthetized to prepare the ischemia/reperfusion model. The left anterior descending branch was ligated (successful surgery was confirmed by observing the cyanosis around the remote end of myocardium and ST-segment elevation and tall T-waves in ECG), after 30 min of ligation, $2 \mathrm{~h}$ of reperfusion was initiated by removing the ligation line.

Coagulation indicators. Two drops of blood from the rat-tail vein were collected in a glass tube to measure the clotting time. A total of $4 \mathrm{ml}$ of blood was collected from the abdominal aorta in a vacuum tube containing anticoagulant (3.8\% sodium citrate: Whole blood, 1:9). The blood was centrifuged at $1,016 \mathrm{x}$ g for $15 \mathrm{~min}$ to collect plasma, at room temperature. Plasma was separated to measure the PT, TT and APTT, according to their kit instructions. Plasma levels of Von Willebrand factor (vWF) were assessed using a vWF ELISA kit (cat. no. H274; Nanjing Jiancheng Biological Technology Co., Ltd., Nanjing, China).

Annexin V and PI staining for cardiomyocyte apoptosis. Apoptosis of cardiomyocytes was measured using flow cytometry. In brief, a $5 \mathrm{~mm}^{3}$ sample $(\sim 70 \mathrm{mg})$ of the left ischemic myocardium was obtained following reperfusion. The ischemic myocardium was then washed in D-Hanks solution and digested in $10 \mathrm{ml} 0.08 \%$ trypsin for $5 \mathrm{~min}$ at room temperature. The suspension was filtered through a 200-micron mesh nylon filter to collect the filtrate, then, $10 \mathrm{ml}$ culture medium containing calf serum was added to terminate the digestion. After centrifugation of the suspension for $10 \mathrm{~min}$, at $1,016 \mathrm{x} \mathrm{g}$ and room temperature, the supernatant was discarded, and cells were resuspended in $5 \mathrm{ml}$ culture medium containing calf serum. Cells were then washed with PBS and resuspended in a binding buffer. FITC-conjugated Annexin V (3 $\mu \mathrm{l})$ and PI reagent $(3 \mu \mathrm{l})$ were added and the mixture was incubated at room temperature for $20 \mathrm{~min}$. The samples were immediately measured by flow cytometer (FACSCalibur, BD Biosciences, USA). Apoptosis was calculated as the percentage of apoptotic cardiomyocytes (Annexin $\mathrm{V}^{+} / \mathrm{PI}^{-}$) using CellQuest software (ver 4.0; BD Biosciences) (29-31).

Expression of NF- $\kappa B$ and MMP-9. NF- $\kappa \mathrm{B}$ and MMP-9 expression was determined by immunohistochemistry. A $5 \mathrm{~mm}^{3}$ sample of left ischemic myocardium $(\sim 70 \mathrm{mg})$ was obtained from each rat after reperfusion, fixed in $10 \%$ formalin solution for $24 \mathrm{~h}$ at room temperature and embedded in paraffin.
Paraffin-embedded samples were cut into $3 \mu \mathrm{m}$ thick slices and mounted on glass slide. The tissue sections were immersed in 10 volumes of $3 \%$ hydrogen peroxide for $10 \mathrm{~min}$ at $70^{\circ} \mathrm{C}$ to block endogenous peroxidase activity, deparaffinized and then subjected to antigen retrieval with $0.01 \mathrm{mmol} / 1$ citrate solution (pH 6.0) for $50 \mathrm{sec}$ at $80-90^{\circ} \mathrm{C}$. Next, the sections were washed in PBS. After treatment with $5 \%$ bovine serum albumin (Wuhan Boster Biological Technology. Ltd.) for $20 \mathrm{~min}$ at room temperature, the sections were incubated with the following primary antibodies in a moist chamber: Anti-NF- $\mathrm{KB}$ (1:100; cat. no. BM3940; Wuhan Boster Biological Technology Ltd., China) for $180 \mathrm{~min}$ at $4^{\circ} \mathrm{C}$ and anti-MMP-9 (1:80; cat. no. BA0573; Wuhan Boster Biological Technology. Ltd.) overnight at $4^{\circ} \mathrm{C}$. The sections were washed twice in PBS and incubated with the labeled streptavidin-biotin complex (1:1; cat. no. SA1022; Wuhan Boster Biological Engineering Co. Ltd.) for $30 \mathrm{~min}$ at $37^{\circ} \mathrm{C}$. The slices were colored with diaminobenzylamine chromogenic reagent at room temperature, stained with hematoxylin, dehydrated, permeabilized and sealed, according to immunohistochemical staining kit instructions (NF- $\mathrm{kB}$, cat. no. BM3940; MMP-9 cat no. BA0573; Wuhan Boster Biological Engineering Co. Ltd.). The slides were examined under a light microscope at $\mathrm{x} 400$ magnification, eight slides per group and five fields of view per slide (32). MMP-9 and NF- $\mathrm{kB}$ expression were assessed as described in the literature using an Olympus BX51 positive position microscope for image analysis (Olympus Corporation, Tokyo, Japan), using immunohistochemical method and transmission method for qualitative and quantitative analysis. Images were further analyzed with Image Pro Plus 6.0 (Media Cybernetics, Inc., Rockville, MD, USA). Using the transmission method, gray levels of each IHC image of MMP-9 and NF- $\mathrm{kB}$ staining were taken. Gray levels range from 0 to 255 , where white is 255 and black is 0 . Through the combination of trichromatic color shades, a variety of colors can be formed, where the smaller the gray scale, the deeper color, which can be used to indicate higher expression levels. In the present study, the expression of MMP-9 or NF- $\mathrm{kB}$ was calculated as $=255$-their respective gray levels. 

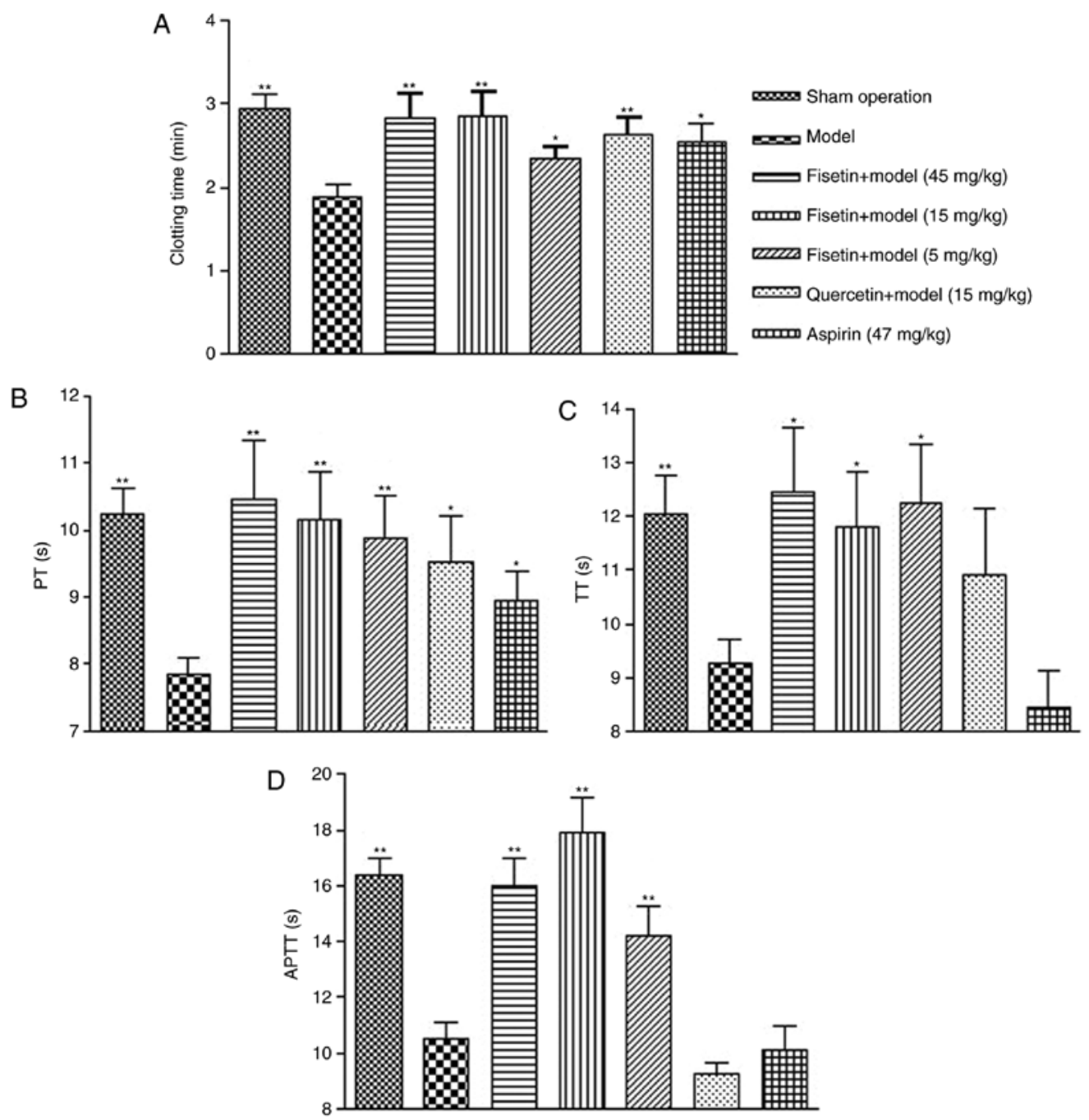

Figure 2. Fisetin significantly prolongs coagulation in a rat model of myocardial ischemia/reperfusion injury. (A) Whole blood clotting time was significantly prolonged in fisetin-pretreated groups. (B) PT was significantly prolonged in fisetin-pretreated groups. (C) TT was significantly prolonged in fisetin-pretreated groups. (D) APTT was significantly prolonged for fisetin-pretreated groups. ${ }^{*} \mathrm{P}<0.05$ and ${ }^{* *} \mathrm{P}<0.01$ vs. model group. $\mathrm{PT}$, prothrombin time; TT, thrombin time; APTT, activated partial thromboplastin time.

Evaluation of myocardial infarct size (IS). To evaluate myocardial IS, 2,3,5-triphenyltetrazolium (TTC) staining was used. After $2 \mathrm{~h}$ of reperfusion, rat hearts were harvested (four samples per group) and then immersed in $1 \%$ TTC buffer for $20 \mathrm{~min}$ at $37^{\circ} \mathrm{C}$. The tissues were then incubated at $-20^{\circ} \mathrm{C}$ for $20 \mathrm{~min}$. Subsequently, the hearts were washed with saline and attached blood vessels and fat removed. Serial $1 \mathrm{~mm}$ sections from the tip of the heart to the base of the heart were prepared. Viable myocardium was stained deep-red, penumbra was stained light-red and infracted/necrotic myocardium stained pale grey or remained unstained, as previously described (33). The sections were viewed under a light microscope (Nikon Corporation, Tokyo, Japan; magnification, $\mathrm{x} 400$ ). The area of the myocardium stained grey was assessed with Image Pro Plus 6.0 (Media Cybernetics, Inc.) (34-37). A higher density of staining suggested that more viable myocardial cells remained (38).

Examination of pathological changes in myocardial cells. $\mathrm{H} \& \mathrm{E}$ staining was used to examine the pathological changes in the myocardial cells. Hearts were excised, washed with

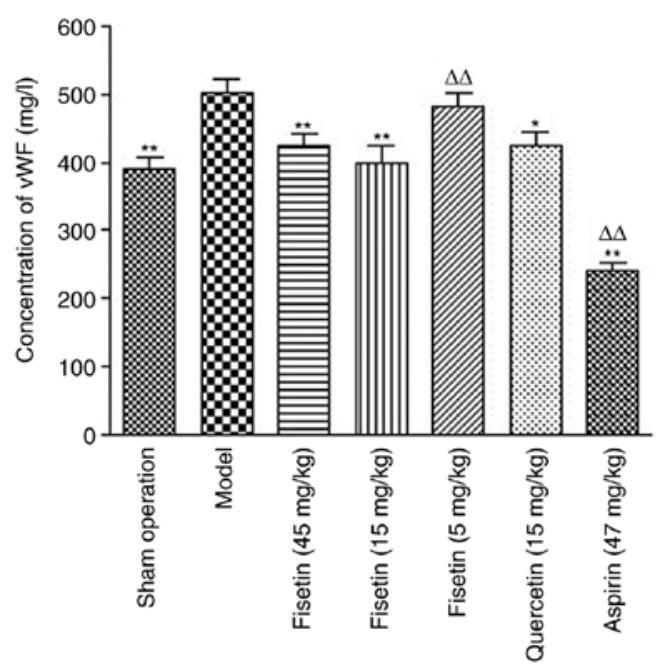

Figure 3. Fisetin treatment ( 15 and $45 \mathrm{mg} / \mathrm{kg}$ ) significantly reduces plasma vWF levels in rats with myocardial ischemia/reperfusion injury. (A) Quantification of vWF in rat-tail blood samples measured by ELISA. ${ }^{*} \mathrm{P}<0.05$ and ${ }^{* *} \mathrm{P}<0.01$ vs. model group; ${ }^{\Delta \Delta} \mathrm{P}<0.01$ vs. sham group. vWF, Von Willebrand factor. 


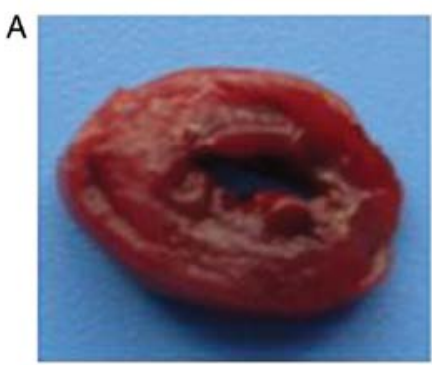

Sham operation

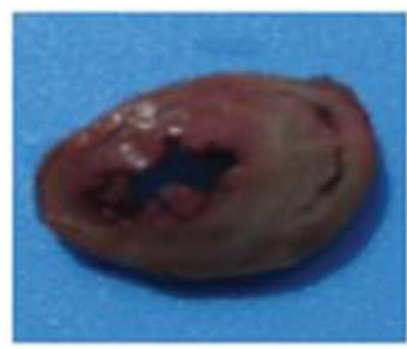

Fisetin $15 \mathrm{mg} / \mathrm{kg}+$ model

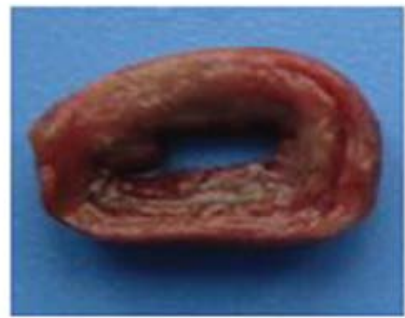

Aspirin $47 \mathrm{mg} / \mathrm{kg}+$ model

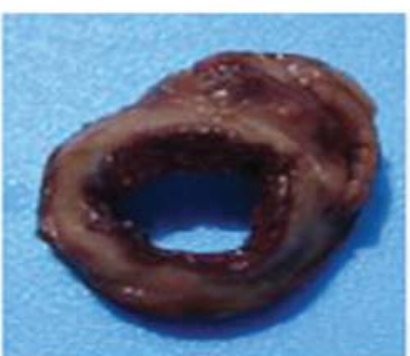

Model

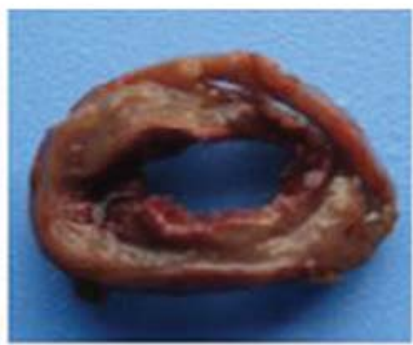

Fisetin $5 \mathrm{mg} / \mathrm{kg}+$ model

B

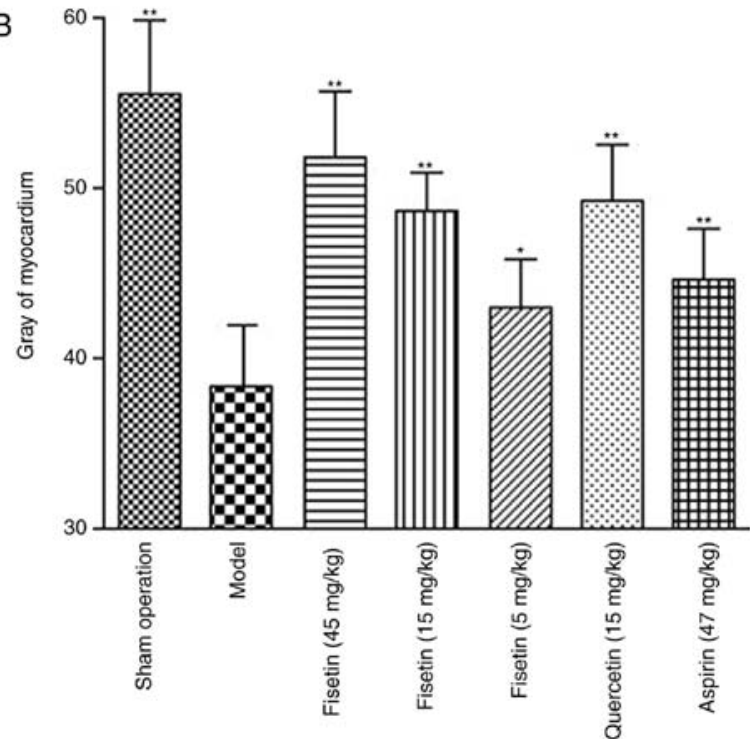

Figure 4. Fisetin reduces acute myocardial ischemia/reperfusion injury in the rat model. (A) Images of rat myocardial tissue stained with 2,3,5-triphenyltetrazolium following acute myocardial ischemia/reperfusion injury. (B) Quantification of infracted/necrotic tissue (gray staining). ${ }^{*}<0.05$ and ${ }^{* * *} \mathrm{P}<0.01 \mathrm{vs}$. model group.

ice-cold PBS, and $1 \mathrm{~mm}$ thick coronal slices prepared after the hearts were snap frozen at $-20^{\circ} \mathrm{C}$ for $20 \mathrm{~min}$. The slices were fixed directly in $10 \%$ neutral formalin for $24 \mathrm{~h}$ at room temperature and paraffin-embedded., Sections $(3 \mu \mathrm{m}$ thickness) were prepared from paraffin-embedded tissue blocks by dehydration through a graded ethanol series and clearing with xylene for H\&E staining (for $12 \mathrm{~min}$ at room temperature). Morphological changes in the myocardial tissues were evaluated as previously described, using an Olympus light microscope (magnification, x400) $(39,40)$.

Statistical methods. Data were presented as mean \pm standard error of the mean. One-way analysis of variance followed by Dunnett's test was used for comparisons of more than two groups. Statistical analyses were performed using SPSS 13.0 (SPSS, Inc., Chicago, IL, USA) statistical software package. $\mathrm{P}<0.05$ was considered to indicate statistical significance.

\section{Results}

Fisetin significantly prolongs coagulation in rats with myocardial ischemia/reperfusion injury. The whole blood clotting time (CT) of rats in the group pretreated with fisetin was significantly prolonged compared with the model group $(\mathrm{P}<0.01$ for 15 and $45 \mathrm{mg} / \mathrm{kg}$ fisetin; $\mathrm{P}<0.05$ for $5 \mathrm{mg} / \mathrm{kg}$ fisetin; Fig. 2A). CT was comparable between groups pretreated with fisetin (15 or $45 \mathrm{mg} / \mathrm{kg}$ ) and groups pretreated with quercetin $(15 \mathrm{mg} / \mathrm{kg})$ or aspirin $(47 \mathrm{mg} / \mathrm{kg})$. Similar results were observed for PT, TT, and APTT. Fisetin treatment (5, 15 , or $45 \mathrm{mg} / \mathrm{kg}$ ) significantly prolonged PT, TT, and APTT in a dose dependent manner (Fig. 2B-D). Similarly, quercetin $(15 \mathrm{mg} / \mathrm{kg})$ and aspirin $(47 \mathrm{mg} / \mathrm{kg})$ significantly improved PT compared with the model group $(\mathrm{P}<0.05)$. Of note, the anticoagulant effect of fisetin was superior to quercetin and aspirin. 


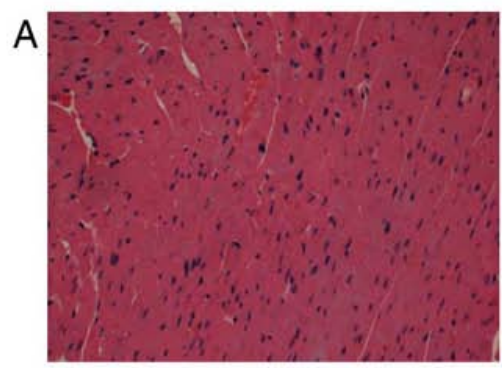

Sham operation

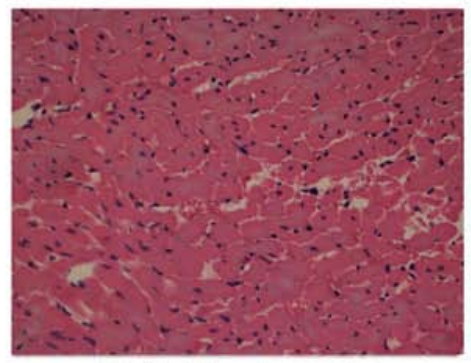

Fisetin $15 \mathrm{mg} / \mathrm{kg}+$ model

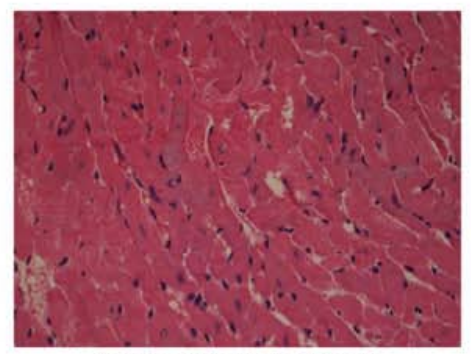

Aspirin 47 mg/kg+model

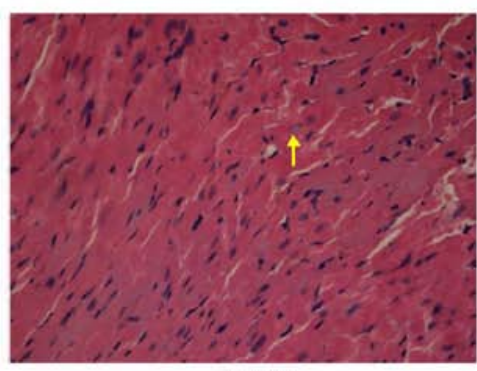

Model

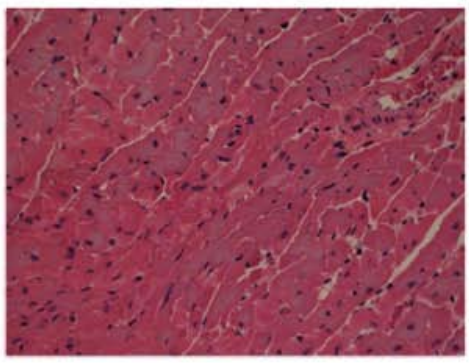

Fisetin $5 \mathrm{mg} / \mathrm{kg}+$ model

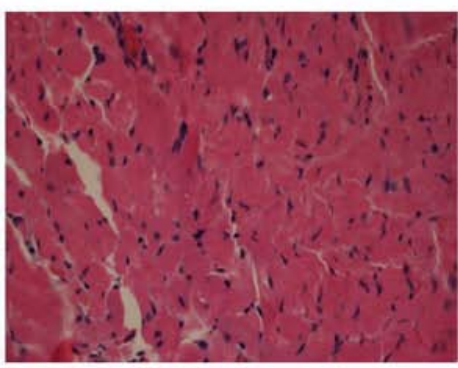

Fisetin $45 \mathrm{mg} / \mathrm{kg}+$ model

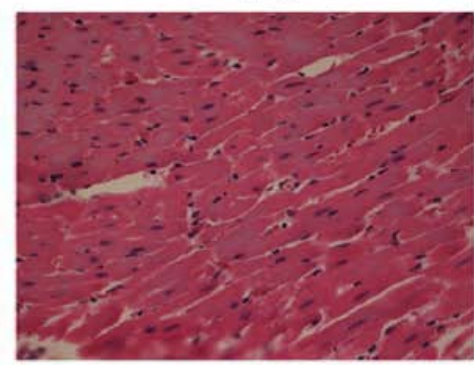

Quercetin 15 mg/kg+model

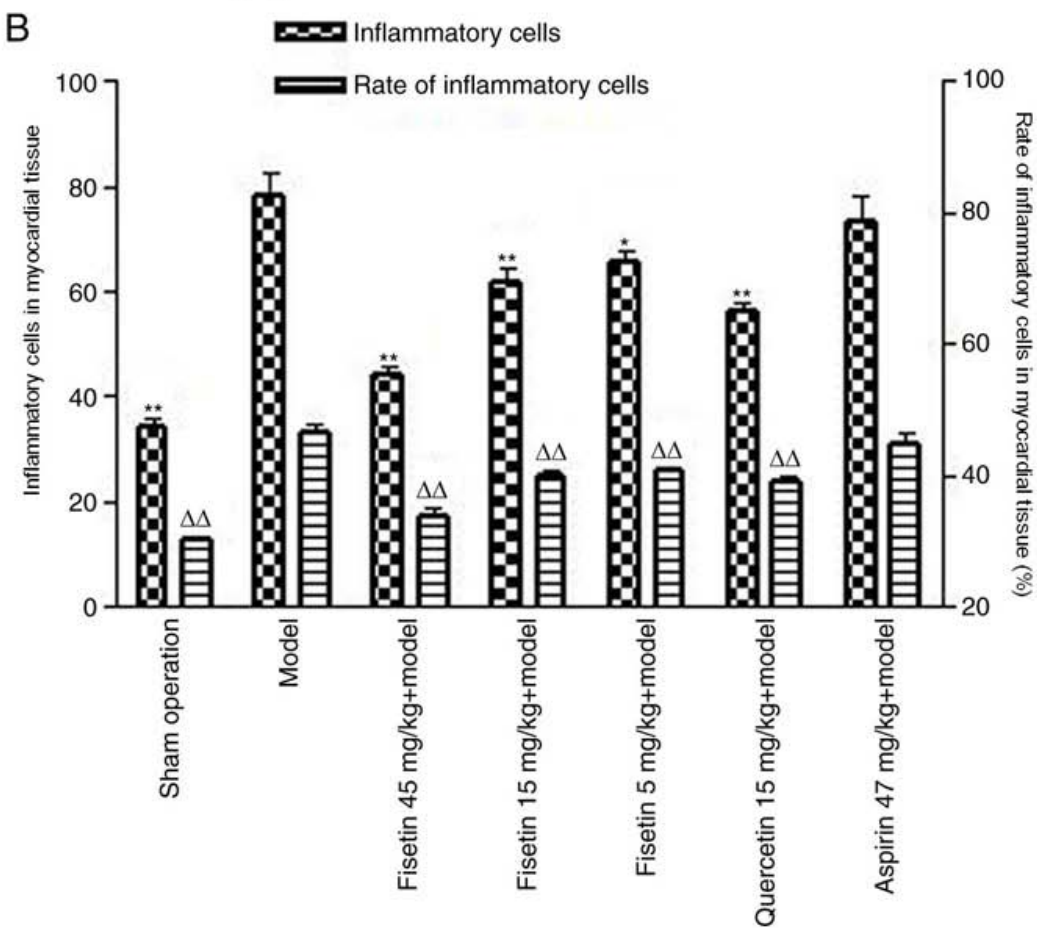

Figure 5. Fisetin alters cardiomyocyte morphology. (A) Hematoxylin and eosin-stained sections of rat heart tissue following myocardial ischemia/reperfusion (magnification, x400). Myocardial cells in fisetin-pretreated group showed less notable structural changes as well as reduced number of inflammatory cells compared with the model group. The yellow arrow indicates inflammatory cells (infiltrating neutrophils). (B) Inflammatory cell number and the proportion of inflammatory cells, in myocardial tissue, were significantly decreased in fisetin-pretreated groups compared with the model group. ${ }^{*} \mathrm{P}<0.05$ and ${ }^{* *} \mathrm{P}<0.01$ vs. inflammatory cell model; ${ }^{\Delta \Delta} \mathrm{P}<0.01$ vs. rate of inflammatory model group.

Fisetin significantly reduces plasma $v W F$ in rats with myocardial ischemia/reperfusion injury. Plasma vWF levels in fisetin (15 and $45 \mathrm{mg} / \mathrm{kg}$ ) pretreated groups were significantly lower than the model group ( $\mathrm{P}<0.01$; Fig. 3 ), which suggested that fisetin may inhibit platelet aggregation by reducing the levels of vWF.

Fisetin reduces acute myocardial ischemia/reperfusion injury in rats. TTC staining was used to investigate the effects of fisetin on acute myocardial ischemia/reperfusion injury
(Fig. 4A). The infarct areas in the groups pretreated with fisetin were significantly reduced compared with the model group in a dose-dependent manner ( $\mathrm{P}<0.01$; Fig. 4B).

Fisetin alters morphological presentation of cardiomyocytes. In the sham group, the myocardial fibers were arranged in an orderly manner, the horizontal grain structure was clear and there were almost no inflammatory cells (Fig. 5A). The presence of inflammatory cells within myocardial fibers would indicate neutrophil infiltration, a common occurrence 

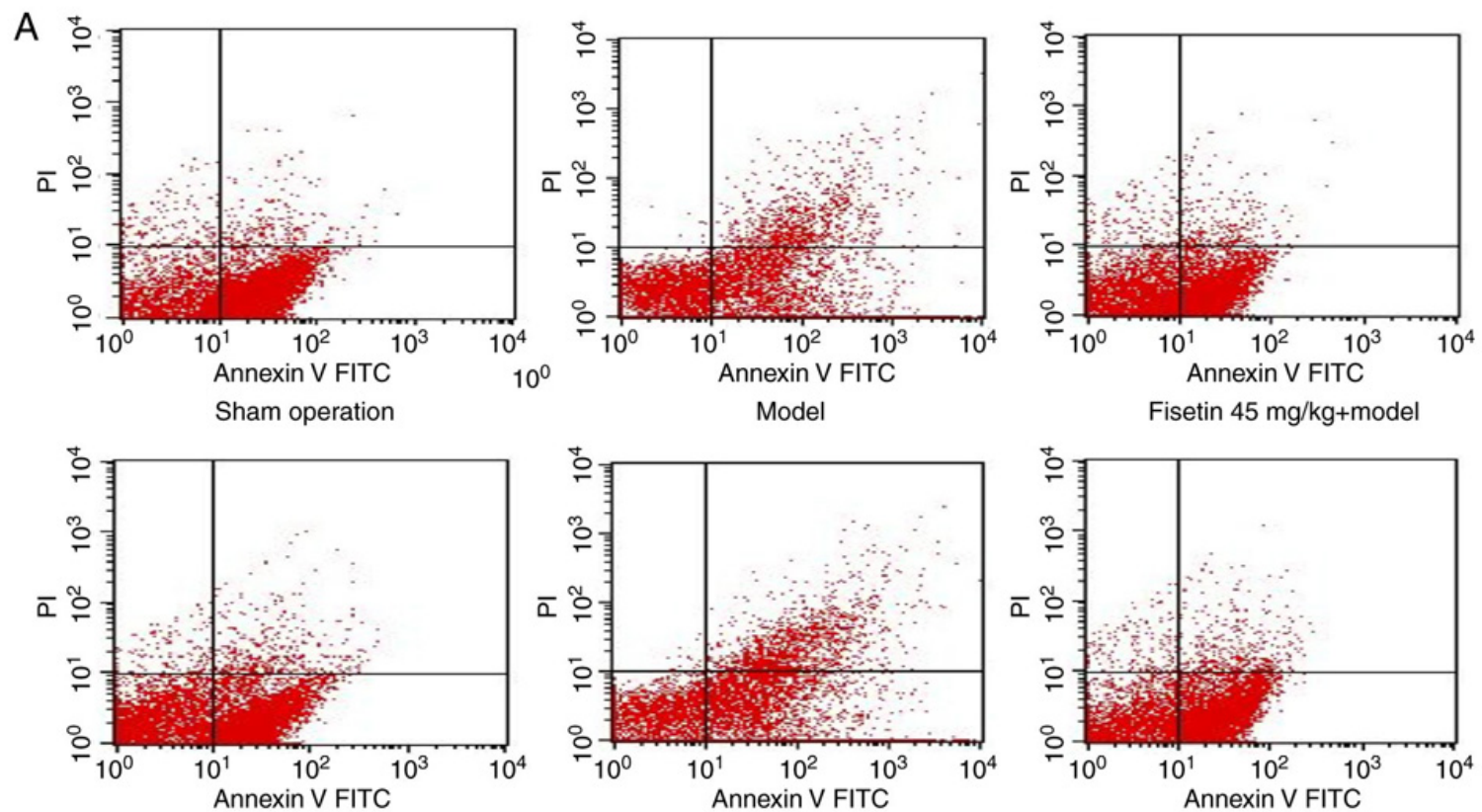

Fisetin $15 \mathrm{mg} / \mathrm{kg}+$ model

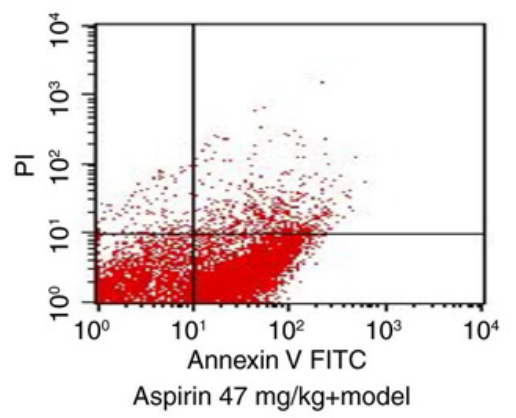

Fisetin $5 \mathrm{mg} / \mathrm{kg}+$ model

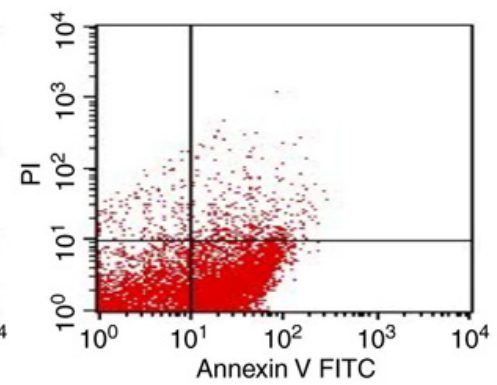

Quercetin $15 \mathrm{mg} / \mathrm{kg}+$ model

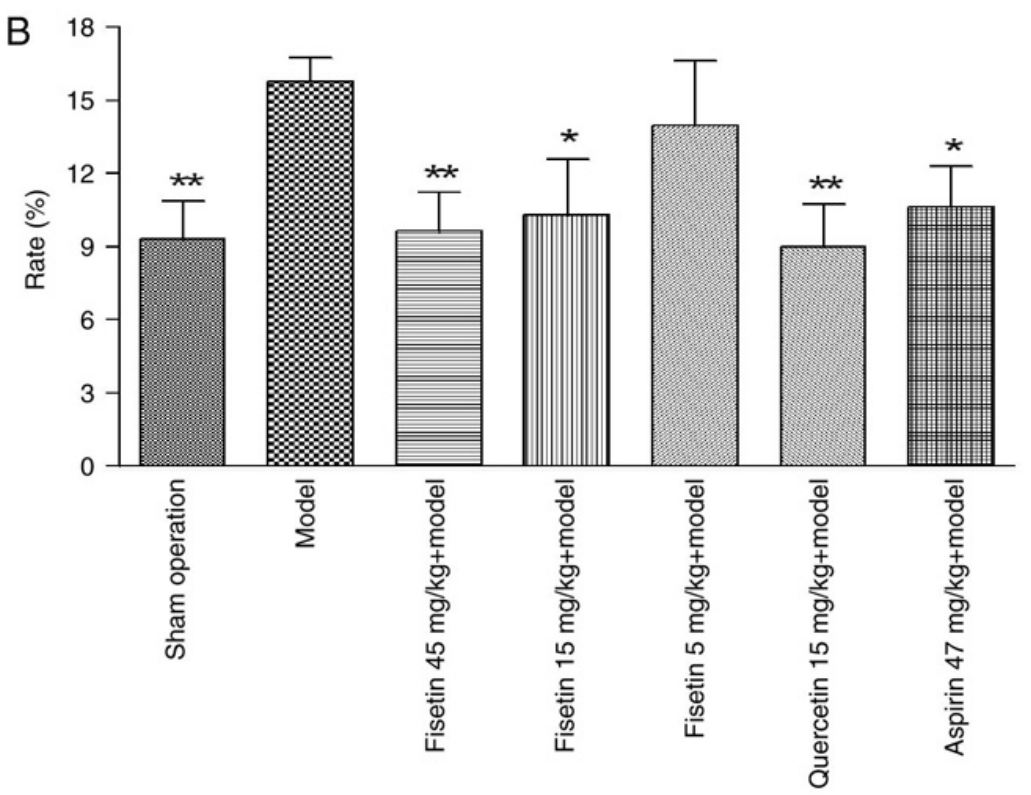

Figure 6. Fisetin reduces apoptosis of cardiomyocytes (A) Flow cytometry analysis with Annexin V-FITC/PI staining. (B) Quantification of cardiomyocyte apoptosis rate in UR quadrant (upper right quadrant). Fisetin $(15 \mathrm{or} 45 \mathrm{mg} / \mathrm{kg}$ ) significantly decreased the percentage of apoptotic cardiomyocytes, compared with the model group. Fisetin inhibited apoptosis of myocardial cells in a dose dependent manner. ${ }^{*} \mathrm{P}<0.05$ and ${ }^{* *} \mathrm{P}<0.01$ vs. model group. FITC, fluorescein isothiocyanate; PI, propidium iodide.

in myocardial ischemia-reperfusion injury. In the myocardial ischemia/reperfusion model group, the myocardial fibers were arranged irregularly and their structure was disordered. Parts of the horizontal grain structure were not clear or had disappeared, the gaps between muscle fibers had widened, some of the myocardial cells appeared necrotic and there were numerous inflammatory cells in the myocardial matrix (Fig. 5A). Compared with the model group, myocardial cells in the fisetin-pretreated group demonstrated less notable structural changes and a reduced number of inflammatory cells (Fig. 5A). Fisetin-pretreated groups demonstrated less disarrangement of cardiac muscle filaments, decreased cardiomyocyte edema or phagocytic cells, reduced disrupted myofilaments, and less membrane rupture and nuclear swelling when compared to the myocardial ischemia reperfusion group (Fig. 5A). By counting the number of infiltrative neutrophils, dividing this by the number of cardiomyocytes in the same field of vision and multiplying by 100 the proportion of infiltrating inflammatory cells was estimated. Inflammatory cell counts, and the proportions of inflammatory cells in myocardial tissue were also significantly decreased in the fisetin-pretreated groups (Fig. 5B).

Fisetin reduces apoptosis in cardiomyocytes. Flow cytometry analysis with annexin V/PI staining was performed to determine the effect of fisetin on cardiomyocyte apoptosis. Compared with 


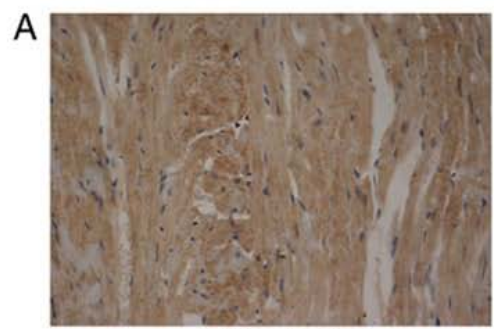

Sham operation

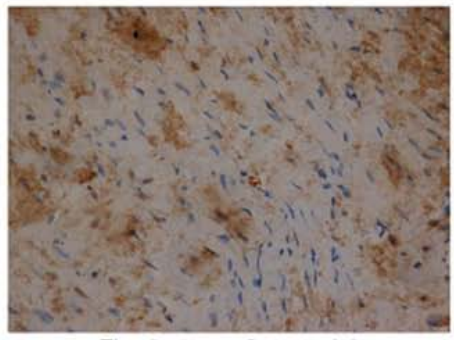

Fisetin $15 \mathrm{mg} / \mathrm{kg}+$ model

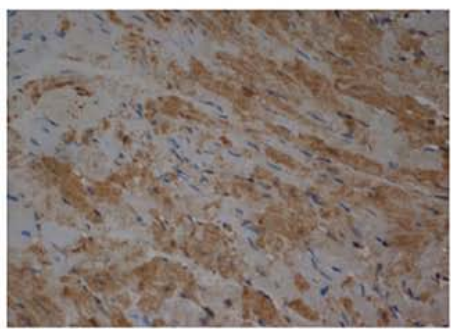

Aspirin $47 \mathrm{mg} / \mathrm{kg}+$ model

$\square$

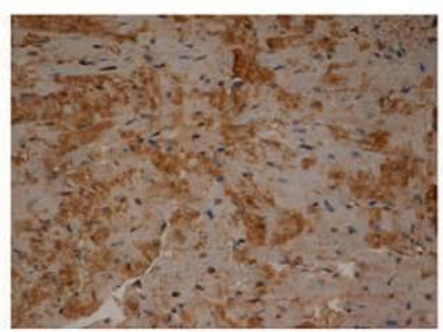

Model

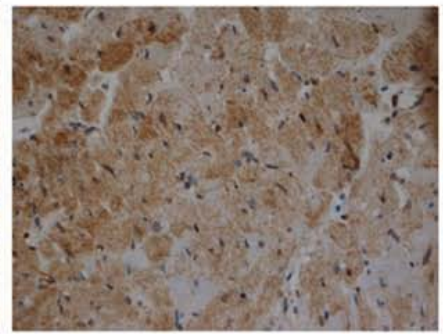

Fisetin $5 \mathrm{mg} / \mathrm{kg}+$ model

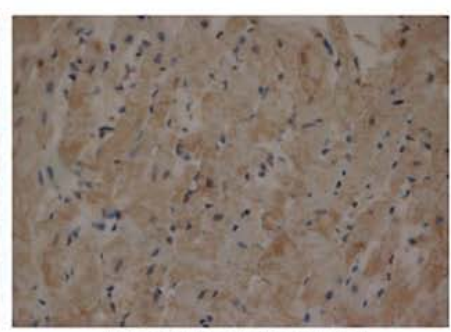

Fisetin $45 \mathrm{mg} / \mathrm{kg}+$ model

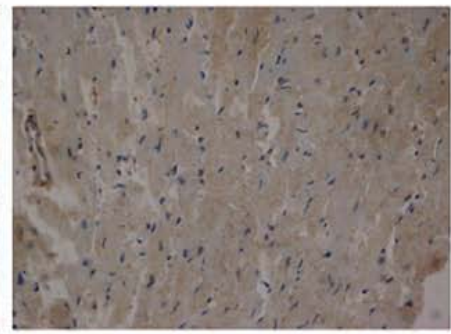

Quercetin $15 \mathrm{mg} / \mathrm{kg}+$ model

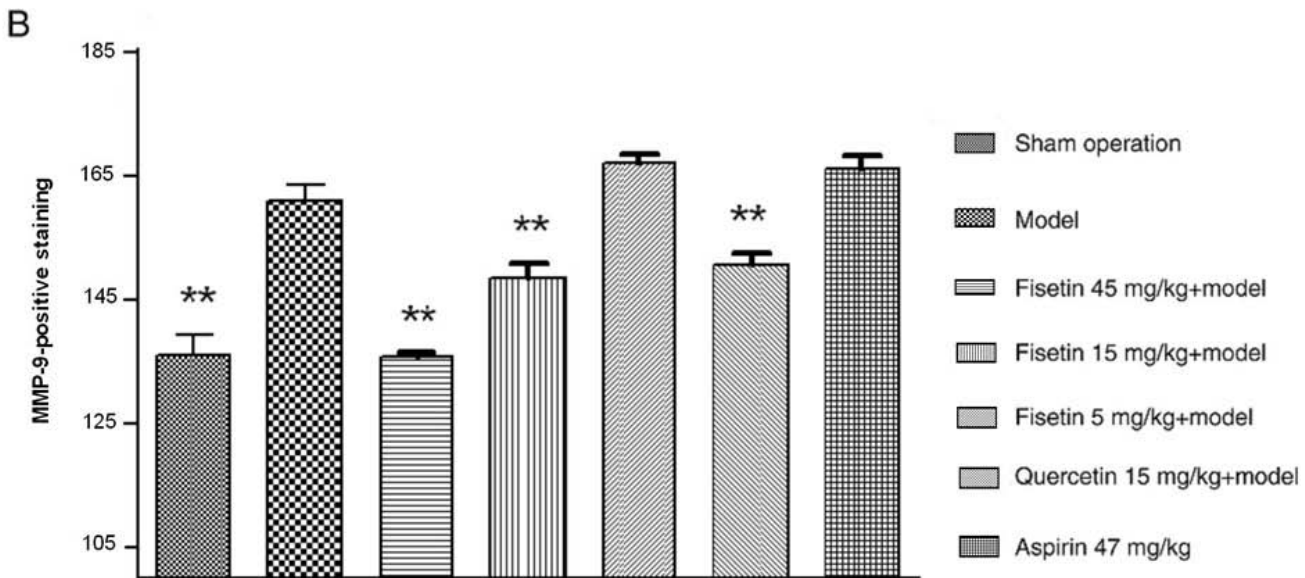

Figure 7. Fisetin reduces MMP-9 expression in ischemic myocardium. (A) Representative photomicrographs of rat ischemic myocardium stained for MMP-9 (brown; magnification, x400). (B) Quantification of MMP-positive staining. The expression of MMP-9 was markedly inhibited in fisetin-pretreated groups (15 and $45 \mathrm{mg} / \mathrm{kg}) .{ }^{* *} \mathrm{P}<0.01$ vs. model group. MMP, matrix metalloproteinase.

the model group, fisetin treatment $(15$ or $45 \mathrm{mg} / \mathrm{kg})$ significantly decreased the percentage of apoptotic cardiomyocytes $(\mathrm{P}<0.01$ or $\mathrm{P}<0.05$; Fig. 6 ). These results indicated that fisetin inhibited apoptosis of myocardial cells in the rat model of ischemia/reperfusion injury in a dose dependent manner.

Fisetin reduces $N F-\kappa B$ and MMP-9 expression in ischemic myocardium. The expression of MMP-9 was significantly attenuated in fisetin (15 and $45 \mathrm{mg} / \mathrm{kg}$ ) pretreated groups compared with the model group $(\mathrm{P}<0.01$; Fig. 7A and $\mathrm{B})$. $\mathrm{NF}-\kappa \mathrm{B}$ was stained yellow/brown and mainly appeared in the cytoplasm for the sham group. The model group showed abundant expression of $N F-\kappa B$ with a significant shift to the nucleus. NF- $\kappa \mathrm{B}$ expression was significantly inhibited in fisetin and quercetin-pretreated groups compared with the model group, demonstrating decreased $\mathrm{NF}-\kappa \mathrm{B}$ expression with wide cytoplasmic distribution $(\mathrm{P}<0.01$; Fig. $8 \mathrm{~A}-\mathrm{C})$.

Fisetin significantly reduces platelet aggregation rate in human blood samples. The effect of fisetin on platelet aggregation was further tested in human blood samples in vitro. The rates of platelet aggregation following fisetin $\left(1 \times 10^{-9}-1 \times 10^{-5} \mathrm{M}\right)$, dipyridamole $\left(2 \times 10^{-6} \mathrm{~mol} / \mathrm{l}\right)$, clopidogrel $\left(3 \times 10^{-5} \mathrm{~mol} / \mathrm{l}\right)$, and aspirin $\left(2.8 \times 10^{-4} \mathrm{~mol} / \mathrm{l}\right)$ treatments were significantly lower 


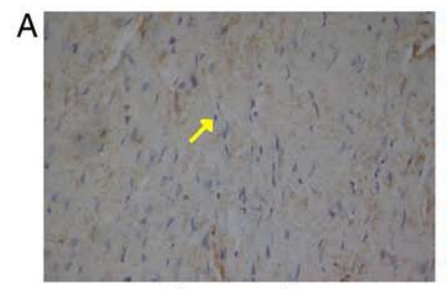

Sham operation

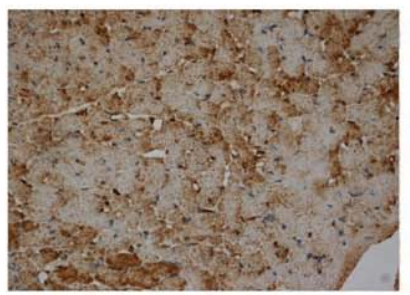

Fisetin $15 \mathrm{mg} / \mathrm{kg}+$ model

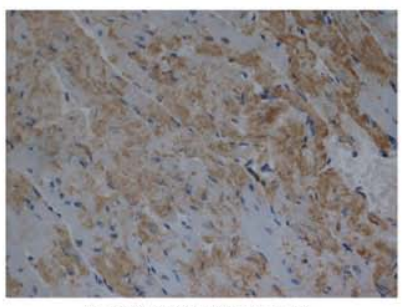

Aspirin $47 \mathrm{mg} / \mathrm{kg}+$ model

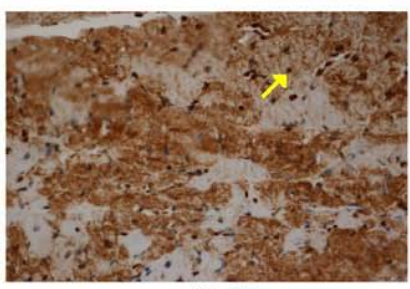

Model

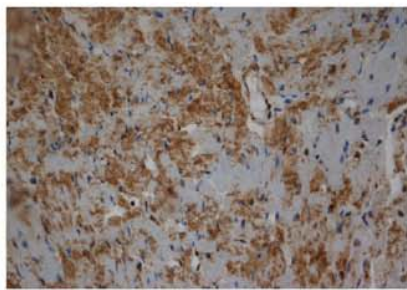

Fisetin $5 \mathrm{mg} / \mathrm{kg}+$ model

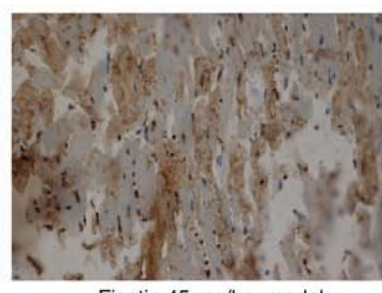

Fisetin $45 \mathrm{mg} / \mathrm{kg}+$ model

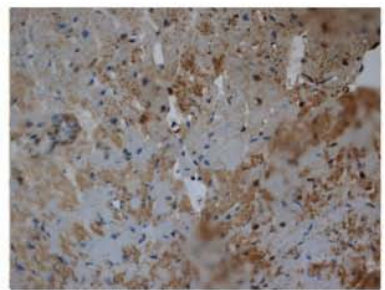

Quercetin $15 \mathrm{mg} / \mathrm{kg}+$ model
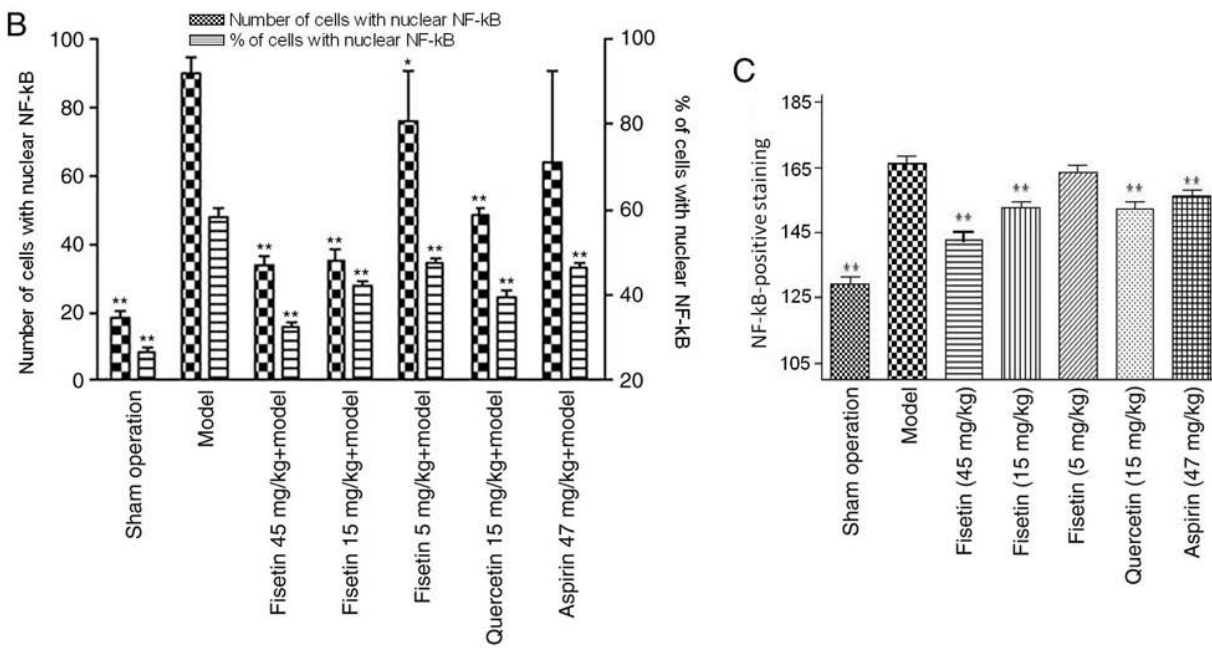

Figure 8. Fisetin reduces NF- $\kappa$ B expression in ischemic myocardium. (A) Representative photomicrographs of rat ischemic myocardium stained for NF- $\kappa$ B (yellow brown; magnification, $\mathrm{x} 400$ ). Yellow arrow in the sham operation group highlights a cell nucleus with no NF- $\kappa \mathrm{B}$ localization (stained blue) and the yellow arrow in the model group indicates a cell nucleus showing translocation of NF- $\kappa$ B expression from cytoplasm to nucleus (stained yellow/brown). (B) NF- $\kappa$ B nuclear expression was significantly inhibited in fisetin and quercetin-pretreated groups compared with the model group. (C) Quantification of total NF- $\kappa \mathrm{B}$ staining. ${ }^{*} \mathrm{P}<0.05$ and ${ }^{* *} \mathrm{P}<0.01$ vs. model group. $\mathrm{NF}-\kappa \mathrm{B}$, nuclear factor $-\kappa \mathrm{B}$.

compared with the control group ( $\mathrm{P}<0.01$; Fig. 9A). In addition, the antiplatelet coagulation of fisetin and quercetin was dose dependent with half maximal inhibitory concentration of $4.54 \times 10^{-7} \mathrm{~mol} / 1$ and $2.71 \times 10^{-7} \mathrm{~mol} / 1$ for fisetin and quercetin, respectively (Fig. 9B).

\section{Discussion}

Flavonoids are 2-phenyl chromone natural compounds found in plants, which promote growth, development, flowering, fruition, and prevent bacterial diseases. Flavonoids have been demonstrated to protect against multiple liver and cardiovascular disorders by virtue of their antibacterial, antiviral, antitumor, antioxidant, anti-inflammatory, and analgesic properties $(6,7)$. The present study tested the antiplatelet coagulation effect of fisetin in a rat model of myocardial ischemia/reperfusion injury, and compared the effect with that of quercetin and aspirin (positive controls). The aim was to demonstrate the antiplatelet effect of fisetin against ischemia/reperfusion injury and to confirm the effect of fisetin on MMP-9 and NF- $\kappa \mathrm{B}$ expression.

Coagulation parameters, CT, APTT, PT and TT, are typically used to assess anticoagulation. CT and APTT reflect the functional status of the intrinsic coagulation system, PT reflects 

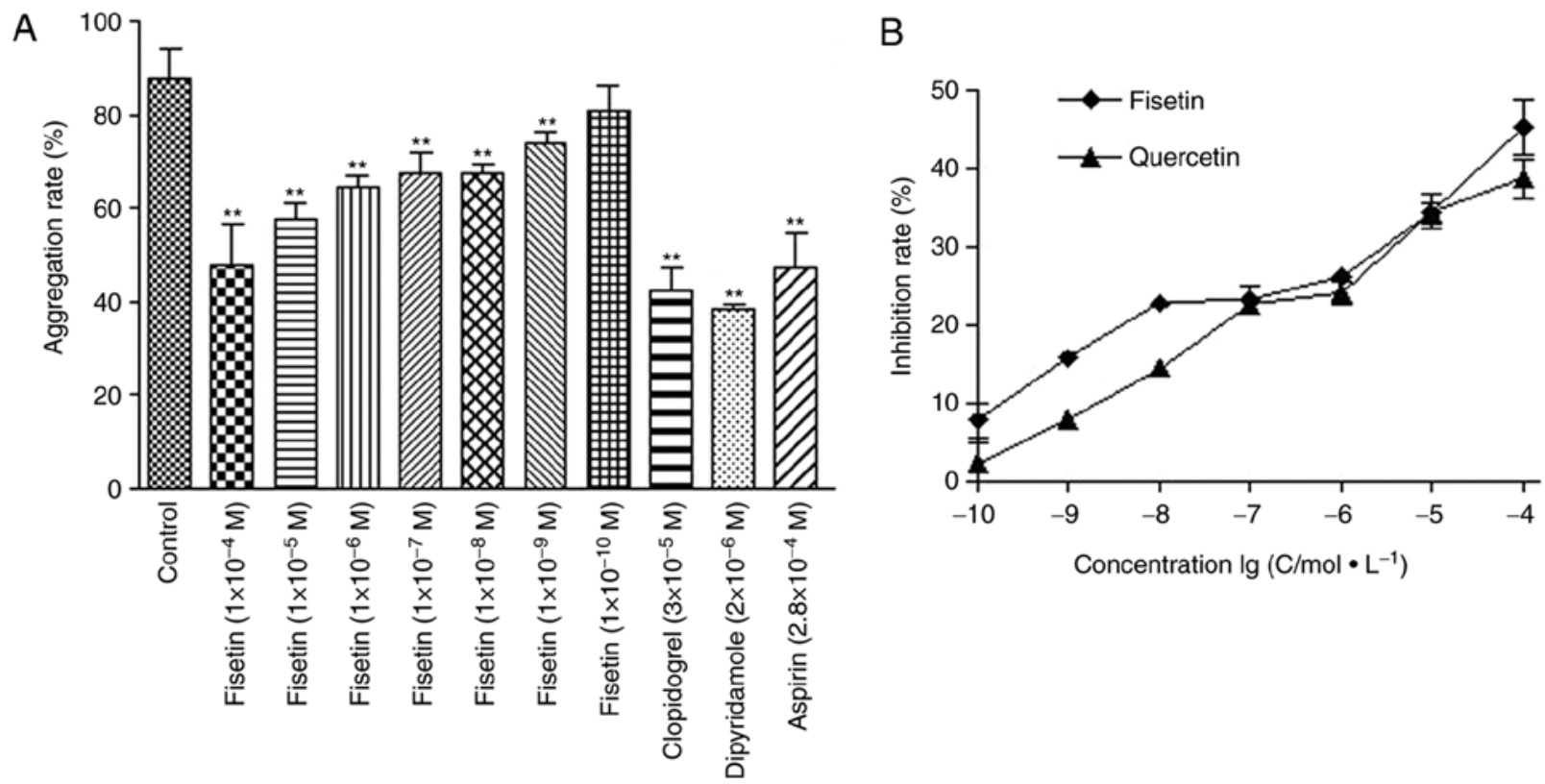

Figure 9. Fisetin significantly reduces platelet aggregation rate in human blood samples. (A) Rate of platelet aggregation in fisetin (1x10 $\left.10^{-9}-1 \times 10^{-5} \mathrm{M}\right)$, dipyridamole $\left(2 \times 10^{-6} \mathrm{~mol} / \mathrm{l}\right)$, clopidogrel $\left(3 \times 10^{-5} \mathrm{~mol} / \mathrm{l}\right)$, and aspirin $\left(2.8 \times 10^{-4} \mathrm{~mol} / \mathrm{l}\right)$ treated groups was significantly reduced. (B) Antiplatelet effect of fisetin and quercetin was dose dependent with half maximal inhibitory concentration of $4.54 \times 10^{-7} \mathrm{~mol} / 1$ and $2.71 \times 10^{-7} \mathrm{~mol} / 1$ for fisetin and quercetin, respectively. ${ }^{* *} \mathrm{P}<0.01$ vs. control.

the functional status of the extrinsic coagulation system and TT is used to determine the presence or absence of excess anticoagulant in circulation $(41,42)$. The present study demonstrated that fisetin significantly increased CT, PT, APTT and TT in rats due to its remarkable antithrombotic effects (43).

vWF is involved in postvascular injury platelet activation following subendothelial damage leading to collagen exposure (44). Platelet activation induced by vWF and collagen allows platelets to adhere to subendothelial matrix (45), which induces coagulation and the release of ADP from platelet dense granules $(46,47)$. Additionally, vWF has been suggested to be causally involved in the pathogenesis of myocardial infarction (48). Therefore, the present study tested the effect of fisetin on vWF levels, and identified that vWF levels were significantly reduced in fisetin-pretreated groups. These findings suggested that $\mathrm{vWF}$ was also involved in fisetin-triggered antiplatelet coagulation.

Platelet adhesion, aggregation and release are vital steps of thrombosis induced by platelet activation due to factors such as ADP, collagen, thrombin and 5-hydroxytyptamine receptors (49-51). In vitro experiments demonstrated that fisetin strongly inhibited ADP-induced platelet aggregation in blood samples, which suggested that fisetin may be a potential antiplatelet aggregator.

Furthermore, it was also observed that fisetin treatment reduced cardiomyocyte apoptosis in rats. Flow cytometry determined the rate of myocardial apoptosis, whilst morphological changes were observed with H\&E staining. Cardiomyocyte apoptosis has long been reported to serve an important role in exacerbating myocardial ischemia/reperfusion injury and is known to be limited to the infarct zone. Considering that apoptosis is regulated by multiple factors including inflammatory proteins, the expressions of NF- $\mathrm{KB}$ and MMP-9 in myocardial tissues was investigated. NF- $\kappa B$ and MMP-9 expression in fisetin-pretreated groups was significantly downregulated compared with the model group. Tissue expression of MMP-9 in myocardial ischemia-reperfusion is the mechanism of myocardial small blood vessel wall injury, cell edema and white blood cell infiltration $(51,52)$. Early selective inhibition of MMP-9 can significantly reduce the myocardial infarct area (52). Wang et al (53) demonstrated that MMP expression was reduced in rats with myocardial ischemia-reperfusion injury following total flavones of Hippophae rhamnoides pre-treatment. Lee et al identified (54) that fisetin decreases apoptotic cell death and intracellular reactive oxygen species by enhancing the expression of $\mathrm{Cu} / \mathrm{Zn}$-superoxide dismutase as well as phosphorylation of protein kinase $B$ and extracellular regulated kinase (ERK) 1/2. Fisetin significantly decreases apoptosis through inhibition of cleaved caspase- 3 and BCL 2 associated X protein expression, and by enhancing the expression of antiapoptotic enzyme as well as Bcl-2 in $\mathrm{H}_{2} \mathrm{O}_{2}$-stimulated $\mathrm{H} 9 \mathrm{c} 2$ cells (54). Previous studies have determined that fisetin induces cancer cell apoptosis via the mitogen-activated protein kinase signaling pathway, mitochondria-mediated pathway, or inhibiting heat shock transcription factor 1 activity (55-57).

In summary, the present study was the first to evaluate the antiplatelet and antithrombotic effects of fisetin, both in vitro and in vivo. These findings suggested that fisetin protected against myocardial ischemia/reperfusion injury by inhibiting apoptosis and by regulating the signaling pathways involved in the inflammatory and coagulation reaction.

\section{Acknowledgements}

Not applicable. 


\section{Funding}

The study was supported by the Key Research Project of Shaanxi Science and Technology Agency (grant no. 2017SF-345) and the Third Batch Key Construction Projects of Xi'an Medical University (grant no. 2015-97).

\section{Availability of data and materials}

The datasets used and/or analyzed during the present study are available from the corresponding author on reasonable request.

\section{Authors' contributions}

LHL and HLY designed the study. LHL, XMM, LJL, XLH, BQ, HLY, KLZ, JND, KL and KY performed the experiments. Data were collated by XMM and LL and the results of data were discussed by KL, KLZ, BQ and LHL. LHL, XMM and XLH prepared the figures. XM, LJL, KY, HLY and LHL wrote the first draft of the manuscript. All authors read and approved the final version of the manuscript.

\section{Ethics approval and consent to participate}

All animal and healthy human blood experiments were approved and conducted according to the experimental protocol authorized by the Ethical Committee of the First Affiliated Hospital of Xi'an Medical College.

\section{Patient consent for publication}

Not applicable.

\section{Competing interests}

The authors declare that they have no competing interests.

\section{References}

1. Wong CX, Sun MT, Lau DH, Brooks AG, Sullivan T, Worthley MI, Roberts-Thomson KC and Sanders P: Nationwide trends in the incidence of acute myocardial infarction in Australia, 1993-2010. Am J Cardiol 112: 169-173, 2013.

2. Kramarow E, Lubitz $\mathrm{J}$ and Francis $\mathrm{R} \mathrm{Jr}$ : Trends in the coronary heart disease risk profile of middle-aged adults. Ann Epidemiol 23: 31-34, 2013.

3. Braga JR, Tu JV, Austin PC, Chong A, You JJ, Farkouh ME, Ross HJ and Lee DS: Outcomes and care of patients with acute heart failure syndromes and cardiac troponin elevation. Circ Heart Fail 6: 193-202, 2013.

4. Neri M, Riezzo I, Pascale N, Pomara C and Turillazzi E: Ischemia/reperfusion injury following acute myocardial infarction: A critical issue for clinicians and forensic pathologists. Mediators Inflamm 4: 7018393, 2017.

5. Portt L, Norman G, Clapp C, Greenwood M and Greenwood MT: Anti-apoptosis and cell survival: A review. Biochim Biophys Acta 1813: 238-259, 2011.

6. Wei Q, Yin Y, Xi M, Zhou D, Zhu Y, Guan Y, Guo C, Wang Y, Duan $\mathrm{J}$ and Wen A: Antioxidant properties of magnesium lithospermate B contribute to the cardioprotection against myocardial ischemia/reperfusion injury in vivo and in vitro. J Tradit Chin Med 33: 85-91, 2013.

7. Wang Y, Zhang ZZ, Wu Y, Zhan J, He XH and Wang YL: Honokiol protects rat hearts against myocardial ischemia reperfusion injury by reducing oxidative stress and inflammation. Exp Ther Med 5: 315-319, 2013.
8. Wang L, Ma YT, Xie X, Yang YN, Fu ZY,Li XM, Liu F, Huang Y, Ma X, Chen BD, et al: Interaction between MMP-9 gene polymorphisms and smoking in relation to myocardial infarction in a Uighur population. Clin Appl Thromb Hemost 18: 72-78, 2012.

9. Sinha R, Srivastava S, Joshi A, Joshi UJ and Govil G: In-vitro anti-proliferative and anti-oxidant activity of galangin, fisetin and quercetin: Role of localization and intermolecular interaction in model membrane. Eur J Med Chem 79: 102-109, 2014.

10. Chen PY, Ho YR, Wu MJ, Huang SP, Chen PK, Tai MH, Ho CT and Yen JH: Cytoprotective effects of fisetin against hypoxia-induced cell death in PC12 cells. Food Funct 6: 287-296, 2014.

11. Pasparakis M: Regulation of tissue homeostasis by NF-kappaB signalling: Implications for inflammatory diseases. Nat Rev Immunol 9: 778-788, 2009.

12. Li JL, Chen XL and Sheng LP: Research of the latest brain injury and MMP-9. J Gen Pract: 271-272, 2011.

13. Wagner DR, Delagardelle C, Ernens I, Rouy D, Vaillant M and Beissel J: Matrix metalloproteinase-9 is a marker of heart failure after acute myocardial infarction. J Card Fail 12: 66-72, 2006.

14. Nićiforović N, Mihailović V, Masković P, Solujić S, Stojković A and Pavlović Muratspahić D: Antioxidant activity of selected plant species; potential new sources of natural antioxidants. Food Chem Toxicol 48: 3125-3130, 2010.

15. Valianou L, Stathopoulou K, Karapanagiotis I, Magiatis P, Pavlidou E, Skaltsounis AL and Chryssoulakis Y: Phytochemical analysis of young fustic (Cotinus coggygria heartwood) and identification of isolated colourants in historical textiles. Anal Bioanal Chem 394: 871-882, 2009.

16. Savikin K, Zdunic G, Jankovic T, Stanojkovic T, Juranic Z and Menkovic N: In vitro cytotoxic and antioxidative activity of Cornus mas and Cotinus coggygria. Nat Prod Res 23: 1731-1739, 2009.

17. Tripathi R, Samadder T, Gupta S, Surolia A and Shaha C: Anticancer activity of a combination of Cisplatin and fisetin in embryonal carcinoma cells and xenograft tumors. Mol Cancer Ther 10: 255-268, 2011.

18. Cui EX, Long LH, Zhang JQ, Shao HY and Liu LL: Extracorporeal anticoagulant and dissolving thrombus effects of Fisetin and Quercetin. J Chin Med Mat 32: 1111-1113, 2009 (In Chinese).

19. Park HH, Lee S, Oh JM, Lee MS, Yoon KH, Park BH, Kim JW, Song $\mathrm{H}$ and Kim SH: Anti-inflammatory activity of fisetin in human mast cells (HMC-1). Pharmacol Res 55: 31-37, 2007.

20. Sengupta B, Banerjee A and Sengupta PK: Interactions of the plant flavonoid fisetin with macromolecular targets: Insights from fluorescence spectroscopic studies. J Photochem Photobiol B 80: 79-86, 2005.

21. Ivanova D, Gerova D, Chervenkov T and Yankova T: Polyphenols and antioxidant capacity of Bulgarian medicinal plants. J Ethnopharmacol 96: 145-150, 2005.

22. Sengupta B, Banerjee A and Sengupta PK: Investigations on the binding and antioxidant properties of the plant flavonoid fisetin in model biomembranes. FEBS Lett 570: 77-81, 2004.

23. Yang Y and Qian ZY: Effect of crocetin on platelet aggregation in rats. Chin J Nat Med 5: 374-378, 2007.

24. Cui EX, Long LH, Liu J and Cao YX: Anti-coagulation of cotinus coggygria scop. J Chin Med Mat 30: 202-205, 2007 (In Chinese).

25. Mennander AA, Vuohelainen V, Aanismaa RS, Narkilahti S, Paavonen T and Tarkka M: Sildenafil after cardiac arrest and infarction; an experimental rat model. Scand Cardiovasc J Suppl 47: 58-64, 2013

26. Jin J, Chen F, Wang Q, Qiu Y, Zhao L and Guo Z: Inhibition of TNF- $\alpha$ by cyclophosphamide reduces myocardial injury after ischemia-reperfusion. Ann Thorac Cardiovasc Surg 19: 24-29, 2013.

27. Ding YF, Zhang MM and He RR: Ischemic preconditioning reduces cardiomyocytic apoptosis in rabbit heart in vivo. Sheng Li Xue Bao 52: 220-224, 2000 (In Chinese).

28. Long LH, Cao YX, Ma Z and Liu J: Anticoagulant, anti-aggregation and antithrombotic effects of a novel hexapeptide. J Pharm Pharmacol 63: 1454-1461, 2011.

29. Maulik N, Sasaki H, Addya S and Das DK: Regulation of cardiomyocyte apoptosis by redox-sensitive transcription factors. FEBS Lett 485: 7-12, 2000.

30. Galang N, Sasaki H and Maulik N: Apoptotic cell death during ischemia/reperfusion and its attenuation by antioxidant therapy. Toxicol 148: 111-118, 2000.

31. Gabai VL, Meriin AB, Yaglom JA, Wei JY, Mosser DD and Sherman MY: Suppression of stress kinase JNK is involved in HSP72-mediated protection of myogenic cells from transient energy deprivation. HSP72 alleviates the stewss-induced inhibition of JNK dephosphorylation. J Biol Chem 275: 38088-38094, 2000. 
32. Yu-hui H, Yun F, Fen J and Xing L: Study about cardiomyocyte apoptosis in myocardial ischemic-reperfusion injury of rats and NF- $\kappa$ B p65, iNOS expression. Xi Bao Yu Fen Zi Mian Yi Xue Za Zhi 26: 868-870, 2010 (In Chinese).

33. Yang F, Zhao WL, Mi QY, Xie LP, Liu Z, Zhang W, Li XZ, Huang Y and Ji Y: Assessment of myocardial ischemia-reperfusion injury with two different staining methods. Acta Univ Med Naniing (Nat Sci) 29: 1055-1058, 2009.

34. Fantinelli JC, Gonzalez Arbelaez LF, Perez Nunez IA and Mosca SM: Protective effects of N-(2-mercaptopropionyl)-glycine against ischemia-reperfusion injury in hypertrophied hearts. Exp Mol Pathol 94: 277-284, 2013.

35. Chen J, Petrov A, Yaniz-Galende E, Liang L, de Haas HJ, Narula J and Hajjar RJ: The impact of pressure overload on coronary vascular changes following myocardial infarction in rats. Am J Physiol Heart Circ Physiol 304: H719-H728, 2013.

36. Cao Z, Ren D, Ha T, Liu L, Wang X, Kalbfleisch J, Gao X, Kao R, Williams D and Li C: CpG-ODN, the TLR9 agonist, attenuates myocardial ischemia/reperfusion injury: Involving activation of PI3K/Akt signaling. Biochim Biophys Acta 1832: 96-104, 2013.

37. Bacaksiz A, Teker ME, Buyukpinarbasili N, Inan O, Tasal A, Sonmez O, Erdogan E, Turfan M, Akdemir OC and Ertas G: Does pantoprazole protect against reperfusion injury following myocardial ischemia in rats? Eur Rev Med Pharmacol Sci 17: 269-275, 2013

38. Yu YP, Xu QQ, Zheng MZ and Wei EQ: Light transmission measurement of focal ischemic cerebral infarction in mice. Zhejiang Da Xue Xue Bao Yi Xue Ban 31: 91-93, 2002 (In Chinese).

39. Kou YY, Zha XD, Li YF and Ge RL: The antioxidative effect of Sanwei Tanxiang powder on rats' hearts against myocardial ischemia and reperfusion injury. Zhong Yao Cai 31: 1013-1015, 2008 (In Chinese)

40. Zhang Q, Rui X and Cai D: Protective effect of Ginaton on rat liver microcirculation disturbance following liver xenotransplantation. Zhonghua Yi Xue Za Zhi 80: 706-708, 2000 (In Chinese).

41. Ashraf HS, Hussain I, Siddiqui AA, Ibrahim MN and Khan MU: The outcome of living related kidney transplantation with multiple renal arteries. Saudi J Kidney Dis Transpl 24: 615-619, 2013.

42. Burton TM, Lacey M, Liu F, Yu Y, Monsalvo ML, Lang K and Sander S: One-year follow-up healthcare costs of patients hospitalized for transient ischemic attack or ischemic stroke and discharged with aspirin plus extended-release dipyridamole or clopidogrel. J Med Econ 15: 1217-1225, 2012.

43. Violi F, Basili S, Berger JS and Hiatt WR: Antiplatelet therapy in peripheral artery disease. Handb Exp Pharmacol: 547-563, 2012.

44. Weber R, Brenck J and Diener HC: Antiplatelet therapy in cerebrovascular disorders. Handb Exp Pharmacol: 519-546, 2012

45. Horton S and Augustin S: Activated clotting time (ACT). Methods Mol Biol 992: 155-167, 2013.
46. Papayannis AC, Abdel-Karim AR, Mahmood A, Rangan BV, Makke LB, Banerjee S and Brilakis ES: Association of coronary lipid core plaque with intrastent thrombus formation: A near-infrared spectroscopy and optical coherence tomography study. Catheter Cardiovasc Interv 81: 488-493, 2013.

47. Lv Y, Ren Y, Sun L, Wang S, Wei M and Jia D: Protective effect of $\mathrm{Na}(+) / \mathrm{Ca}(2+)$ exchange blocker KB-R7943 on myocardial ischemia-reperfusion injury in hypercholesterolemic rats. Cell Biochem Biophys 66: 357-363, 2013.

48. Ueno $\mathrm{H}$ and Harrington WF: Temperature-dependence of local melting in the myosin subfragment- 2 region of the rigor cross-bridge. J Mol Biol 190: 59-68, 1986.

49. Manchikanti L, Falco FJ, Benyamin RM, Caraway DL, Kaye AD, Helm S II, Wargo BW, Hansen H, Parr AT, Singh V, et al: Assessment of bleeding risk of interventional techniques: A best evidence synthesis of practice patterns and perioperative management of anticoagulant and antithrombotic therapy. Pain Physician 16 (2 Suppl): SE261-SE318, 2013.

50. Vanstreels L, Molenberghs G and Voigt JU: Secondary stroke prevention: Misguided by guidelines? Acta Cardiol 67: 431-438, 2012.

51. Torres-Urrutia C, Guzmán L, Schmeda-Hirschmann G, Moore-Carrasco R, Alarcón M, Astudillo L, Gutierrez M, Carrasco G, Yuri JA, Aranda E and Palomo I: Antiplatelet, anticoagulant, and fibrinolytic activity in vitro of extracts from selected fruits and vegetables. Blood Coagul Fibrinolysis 22: 197-205, 2011.

52. Joffs C, Gunasinghe HR, Multani MM, Dorman BH Kratz JM, Crumbley AJ III, Crawford FA Jr and Spinale FG: Cardiopulmonary bypass induces the synthesis and release of matrix metalloproteinases. Ann Thorac Surg 71: 1518-1523, 2001.

53. Wang HT, Wang SM, Yun TTS, G. H and Wang ZZ: Effects of sindacom on the expressions of MMP-9 and myocardial ischemia reperfusion injury of rats. J Chin Gerontol 30: 2619-2621, 2010 (In Chinese).

54. Lee JS, Lee JS, Cha KJ, Kim DE, Lee D, Jung SY, Park ES and Kim IS: Fisetin protects $\mathrm{H} 9 \mathrm{c} 2$ cardiomyoblast cells against $\mathrm{H}_{2} \mathrm{O}_{2}$-induced apoptosis through Akt and ERK1/2 signaling pathways. Mol Cell Toxicol 14: 183-192, 2018.

55. Kang KA, Piao MJ, Madduma Hewage SR, Ryu YS, Oh MC, Kwon TK, Chae S and Hyun JW: Fisetin induces apoptosis and endoplasmic reticulum stress in human non-small cell lung cancer through inhibition of the MARK signaling pathway. Tumour Biol 37: 9615-9624, 2016.

56. Kim JA, Lee S, Kim DE, Kim M, Kwon BM and Han CH: Fisetin, a dietary flavonoid, induces apoptosis of cancer cells by inhibiting HSF1 activity through blocking its binding to the hsp70 promoter. Carcinogenesis 36: 696-706, 2015.

57. Kang KA, Piao MJ and Hyun JW: Fisetin induces apoptosis in human nonsmall lung cancer cells via a mitochondria-mediated pathway. In Vitro Cell Dev Biol Anim 51: 300-309, 2015.

This work is licensed under a Creative Commons

Attribution-NonCommercial-NoDerivatives 4.0 International (CC BY-NC-ND 4.0) License. 